Mapping the co-evolution of urban energy systems: pathways of change

Yvonne Rydin y.rydin@ucl.ac.uk (corresponding author)

Bartlett School of Planning, University College London

Wates House, 22 Gordon Street, London WC1H 0QB

Catalina Turcu catalina.turcu@ucl.ac.uk

Bartlett School of Planning, University College London

Wates House, 22 Gordon Street, London WC1H 0QB

Simon Guy simon.guy@manchester.ac.uk

School of Environment and Development, University of Manchester

PO Box 88, Manchester M60 1QD

Patrick Austin padaustin@googlemail.com

UCL Environment Institute, University College London

Pearson Building, Gower Street, London WC1E 6BT 


\title{
Mapping the co-evolution of urban energy systems: pathways of change
}

\begin{abstract}
The interface of a long-standing movement for sustainability at the urban scale and the imperatives of the carbon reduction agenda are driving change in urban energy systems. This paper seeks to address the nature of that change and, in particular, to consider how different pathways of change are emerging. To do this it draws on the co-evolution and pathways literatures to interrogate a database of current urban energy initiatives within the UK. This analysis reveals the multiple pathways of change though which new modes of energy production and consumption are being developed to deliver carbon reductions through the reconfiguring of urban energy systems. The paper concludes with a discussion of the implications of these changes for urban governance and for carbon reductions.
\end{abstract}

\section{Keywords}

Energy; carbon; urban; pathways; co-evolution 


\section{Introduction}

Since the Rio Summit 1982 launched the Local Agenda 21 movement, cities across the world have become sites of action towards the goal of sustainable development (Betsill and Bulkeley 2007). While the sustainability concept is notoriously broad in its potential definition, it almost always involves an engagement with the decarbonisation agenda, in recognition of the severity of the threat of climate change. This tendency has been reinforced by specific urban movements and local government actions focussed on the decarbonisation agenda including: the Transitions Town movement working towards a post-peak oil world; the C40 cities, a group of the world's largest cities under the Clinton Climate Initiative seeking to reduce carbon emissions; the World Mayors Council on Climate and their carbon accounting tool, the Cities Climate Register; the Local Government Climate Roadmap, arising out of the post-Kyoto process; and the Cities for Climate Protection Programme under the aegis of ICLEI (International Centre for Local Environmental Initiatives).

A key element of decarbonisation will be change within energy systems. In the UK the statutory goal of achieving 80\% cuts in carbon emissions by 2050 (DECC 2009) is being twinned with a desire to enhance national energy security (Watson and Devine-Wright 2011). This is leading to a reconsideration of the UK's currently highly centralised energy system (Arthur 1989; Unruh 2000; Unruh 2006) and a subsequent search for new approaches to the delivery of energy and energy services (Bergman and Eyre 2011). Part of this is an emphasis on the potential of decentralised energy generation and distribution, often in urban sites of population concentration. There is thus now a strong congruence between action for urban sustainability and a desire to 
change the energy system that is to say to focus on urban energy systems as a means of decarbonisation and sustainability more broadly.

This paper examines the emergence of urban energy systems as a site of action and change. It begins by widening out the focus from decentralised energy generation and localised distribution to urban energy systems encompassing the whole energy chain within the urban domain. It then draws on the co-evolution and pathways literatures to understand how innovation in urban energy systems occurs within distinct pathways of sociotechnical change. Based on a methodology closely derived from the above literature, an analysis is presented of a database of urban energy initiatives collated during 2010-11. This analysis provides a mapping of current projects seeking to change urban energy systems. It highlights the diversity of pathways that are currently emerging at the urban scale. As well as providing a pluralist account of the changing landscape of energy provision, the paper also provides a discussion, in the final section, of the implications of such diverse change in urban energy systems for urban governance and for achieving carbon reductions. Thus the paper adds to our knowledge of change in urban energy systems through its distinctive use of the co-evolution and pathways literatures to interrogate an original database of contemporary urban energy initiatives.

\section{More than micro-generation: decentralisation as change in urban energy systems}

Much of the current debate surrounding urban energy focuses on the phenomena of the decentralisation of energy supply and, in particular, micro-generation and counter-poses this to the prevailing centralisation in the UK's energy system during 
the $20^{\text {th }}$ century. Such decentralised energy is identified with the generation and distribution of energy taking place within the boundaries of, or located nearby and directly connected, to a building, a group of buildings or a community (HMSO 2004) and is equated with the technology used, i.e.:

- distributed electricity generated by PV, micro-wind and micro-hydro technologies;

- combined heat and power (CHP) generation; and

- decentralised initiatives that provide heat such as biomass, solar thermal and heat pumps (DTI 2006).

It's important to recognise though that the centralist logic of energy network management has not always prevailed, and in fact it only emerged slowly during the nationalized period of utility control (Guy, Graham et al. 1997). Around a century ago, gas and electricity systems were small, localised and fragmented, each area developing its own distinctive standards, technologies, degrees of municipal support, regulation and tariffs (GOS 2008) and this remained so until the 'first era of decentralisation' was ended in with the onset of World War Two (Alanne and Saari 2006). During and following World War Two, the 'nationalised period of utility control' led to rapid expansion of utility networks which became intimately connected with the drive to improve national economic performance and quality of life. Levels of energy consumption, connection to water and waste networks, and levels of telephone ownership all became surrogate indicators for levels of national economic performance (Sleeman 1953). In the search for greater economies of scale, for example, the electricity industry built larger power stations and upgraded the national electricity transmission network. In the space of the twenty years following World 
War Two, generative capacity multiplied seventeen-fold (Reid and Allen 1970). Driven by the basic assumption that economic growth would generate new demands for utility services, network providers became locked into a centralized logic of network management that focused on improving the quantity and quality of the supply of networked services.

However, as Guy and colleagues (1997) have argued, the "whirlpool of change initiated by the introduction of privatization and liberalization of utility markets [during the 1980s] has radically re- oriented the priorities and practices of local utility companies" (p. 203). The result has been a "splintering" of urban energy networks which, in turn, has had profound impacts on the social, spatial and technical logics driving infrastructure provision. While concerns about 'cherry picking and social dumping' of customers have raised critical concerns about the social polarisation effects of the post-nationalisation era, there has also been some cautious acknowledgement that a shift from a supply logic to a marketised logic of energy provision can have some environmental benefits, in particular a greater interest in demand management. Some are even claiming that we are about to enter a 'second era' of decentralisation based on overlapping arguments of energy security, increased efficiency, carbon reductions and affordability (Alanne and Saari 2006; Coaffee 2008; Roberts 2008).

A range of policy measures have been put in place to encourage the transition to this 'second era' (Rydin 2010). On the decentralised energy generation and distribution front, they range from local planning policies requiring on-site renewable energy generation capacity within new developments to targeted subsidies for installation of such technologies. On-site micro-generation has specifically been supported with a dedicated strategy (DTI 2006; BERR 2008), through the Climate Change and 
Sustainable Energy Act (HMSO 2006), with capital cost support available under the Carbon Emissions Reduction Target (CERT, which obliged energy suppliers to incentivise their customers to install energy-efficient measures, including microgeneration) and the removal from planning regulation of domestic installations.

More recently the Feed-in-Tariff (FIT) and Renewable Heat Incentives (RHI) were launched. Under the FIT the major energy suppliers have to make payments to householders and communities who generate their own electricity from renewable or low carbon sources; the scheme guarantees a minimum payment for all electricity generated by the system, as well as a separate payment for the electricity exported to grid. The Renewable Heat Incentive $(\mathrm{RHI})$, launched in March 2011, is a parallel scheme providing financial support to encourage localized heat systems (DECC 2011). However, the FITs have recently been radically cut-back; larger scale installations are no longer eligible and the minimum payments have been significantly reduced (DECC 2011) and overall the take-off of decentralised energy technology can be considered slow in comparison to other countries such as Denmark, Sweden and Germany (Wolfe 2008; Woodman and Baker 2008; Sperling, Hvelplund et al. 2010; Watson and Devine-Wright 2011).

Alongside this emphasis on energy generation and distribution has gone a greater recognition of the role of demand management. The Carbon Emissions Reduction Target (CERT) (see above), Carbon Reduction Commitment (effectively a tax on energy use by large scale consumers), Warm Front (aimed at lower income households) and area retrofitting initiatives by local authorities have all sought to increase energy efficiency across residential, commercial and even industrial sectors. 
Thus, it is important to see energy systems as a chain of energy production, conversion, transmission, distribution and consumption (Alanne and Saari 2006). From this perspective, the issue of change in urban energy systems is wide-ranging, involving aspects of energy demand and use as well as means of generation and distribution (Watson and Devine-Wright 2011). Indeed, without such a perspective, the influences driving, constraining and shaping change in urban energy will not be fully understood (Ackerman, Andersson et al. 2001; Pepermans, Driesen et al. 2005). The approach adopted in this paper, therefore, is to consider urban energy initiatives as those encompassing any aspect of the whole energy chain and operating at the urban or sub-urban scale. As will be shown, many initiatives can encompass a whole package of measures across the links of generation, distribution and use in the energy chain.

\section{Co-evolution and pathways of change in urban energy systems}

A focus on urban energy as decentralised energy generation and distribution has often gone hand-in-hand with consideration of technologies as the sole engine of innovation and change. Guy and Shove argue that energy in the urban environment has too often been cast in terms of a techno-economic model of technology transfer (Guy and Shove 2000). This is a linear model whereby pioneering research leads to pilot projects, which test economic assumptions and technical specifications; after 'optimal performance' is achieved, the 'transfer' of technology on a wider scale is then stimulated through rational economic decision-making. This techno-economic paradigm fails to see how technological innovation is a multi-faceted process in which economic, social and governance dynamics all play their part. 
An alternative is to espouse a co-evolution approach which considers technological and economic but also social and governance changes as driving systems through their mutual inter-connectedness. Co-evolution as a general approach has been widely used in a diverse range of disciplines. It is often used as "a reminder to disciplinary scholars that more aspects are important than they actually study" (Geels 2005). The key feature is the emphasis on connections between heterogeneous elements and the co-construction of those elements. According to Geels and colleagues, change in systems "not only entail new technologies, but also changes in markets, user practices, policy and cultural discourses, and governing institutions" (Geels, P et al. 2008). Co-evolution has thus been employed to describe the relationship between material artefacts and social practices, but also the relationship between specific technologies and more complex socio-technical systems generally (Shove 2003). Studies from this perspective have looked at sustainable built environments (Brand 2005), water supply and personal hygiene (Geels 2005), transitions in transport (Geels 2005) and lighting and energy practices (Crosbie and Guy, 2008). Each of these studies have been concerned to understand how inventors, entrepreneurs, technologies, markets and regulations interplay to shape the growth, evolution and extension of utility networks which are seen to reflect, as well as to shape, the wider socio-political context within which they emerge.

This paper therefore draws on a co-evolution perspective in order to understand current change in urban energy systems - not merely as a discrete series of changes in technologies and associated infrastructure - but as the outcome of ongoing interactions between technologies, political and economic frameworks, and between institutions and social practices, during which these different dimensions 
change or co-evolve together to produce distinct pathways of change. This emphasis on alternative pathways of innovation is becoming more familiar in debates about environmental politics (Jamison 2001; Leach, Scoones et al. 2010), urban development and form (Guy and Marvin 2001; Moore 2007), food (Allen, Fitzsimmons et al. 2003), energy (Marvin, Chappells et al. 1999; Guy 2006), transport (Evans, Guy et al. 2001), architecture (Guy and Farmer 2001; Guy and Moore 2007), environmental justice (Taylor 2000), and social movements (Hess 2007). While applied in different sectors, each of these studies identifies and foregrounds multiple rather than a singular models of sociotechnical change, which represent contrasting webs of social, economic, technical and institutional arrangements supporting them.

This pathways perspective encourages recognition that a wide diversity of imagined urban futures are likely to co-exist within a single city and that we need to think carefully and critically about how particular choices, whether social or technical, prefigure the adoption of a particular direction of travel, while potentially closing off alternative destinations. By abandoning the search for a singular model, researchers and policy makers need to chart the multiplicity of pathways towards what might result in quite different urban futures. Rather than identify best practices or blueprints, the analytical challenge is to examine the tensions and similarities between these emergent pathways, in particular focusing on the different socioeconomic, institutional and technological assumptions and biases built into them. As Guy and Marvin (2001) have argued

environmental debates constitute sites of conflicting interpretations through which an often complex set of actors participate in a continuous process of defining and redefining the nature of the environmental problem itself. Debates about sustainable cities are shaped by 
different social interests, based on different interpretations of the problem and characterized by quite different pathways towards a range of sustainable futures (p. 138).

Adopting a pathways approach then reinforces an understanding of sustainable energy systems as the end product of contested socio-technical processes, implicit within which are alternative technological strategies which, in turn represent distinct philosophies of environmental place-making. Moreover, these energy pathways are neither static, not mutually exclusive, but instead represent a range of options that might overlap, reinforce or clash with each other as they either are rolled out and upscaled, or disrupted and disconnected. Our adoption of the pathways approach in this paper is therefore intended to give some order to alternative configurations of energy systems currently emerging at the urban scale as they engage more or less productively with the national energy system.

\section{Mapping pathways of change in urban energy systems}

This conceptual framing was used to guide our methodology for mapping how UK urban energy initiatives are currently changing energy systems. We put the emphasis on identifying the different combinations of elements that constitute such initiatives. We were interested in how the different elements could create new possibilities in the urban domain. Since this was a mapping exercise, rather than an in-depth study of how a new urban energy system was being constituted in a particular site ${ }^{1}$, there is inevitably some loss of detail and subtleties of the system building process. Instead we have developed a broad categorisation of the heterogeneous elements that constitute an urban energy system, drawing on the co-

\footnotetext{
${ }^{1}$ This was undertaken in another part of the overall study through case study research.
} 
evolution perspective to consider how the systems were assembled and to what pathway of change they might belong.

The database was collated during October 2010 to January 2011 and the main sources were published documents and online material, supplemented by telephone interviews where necessary to gather more information about specific projects. A wide range of grey and secondary literature was consulted including local authorities websites, a number of databases including the Energy Efficiency Partnership for Homes database, DECC's CHP database and case studies from CABE, Sustainable Development Commission, Urban Design Compendium, Low Carbon Community Challenge programme and Sustainability Awards such as RIBA and Ashden Awards. The database aimed to collect information solely on 'urban' energy initiatives defined as those located within in towns and cities with more than 10,000 inhabitants. Initiatives could concern any aspect of the urban energy system understood as the chain of energy production, conversion, transmission, distribution and consumption. They were projects with an element of collective action, whether organised by the public, private or third sector; that is to say that individual behaviour by a single household was excluded as were individual private sector developments unless they had implications for the local energy chain.

We used the co-evolution literature in a pragmatic way to organise and structure information about these projects into a 'matrix' of institutional, economic, social and technological features of the urban energy initiatives. Each of the matrix's four main categories were further subdivided as follows:

- The Governance category was divided according to who led the project: local authorities; private sector bodies; third sector organisations including 
community groups, NGOs or housing associations; and partnership comprising collaboration between public, private and third sector bodies;

- The Economic category looked at: whether a subsidy was in operation; whether pricing measures such as the feed-in-tariff was relevant; whether both forms of economic instrument pertained; or whether there was no such reliance on an economic instrument;

- The Social category tabled information on whether there was: an element of public awareness activity such as general information provision; whether more intensive and active public engagement was involved; whether both forms of public involvement activity were present; or whether there was no apparent public involvement activity at all; and

- The Technological category collected information on fourteen different types of technology ${ }^{2}$ that were involved in these urban energy projects; however within the matrix the emphasis was on whether there was the inclusion of: energy generation technology; technology oriented towards demand management; both; or neither.

The emphasis was on finding as many different kinds of initiatives as possible defined as distinct combinations of these four dimensions of a project. Inevitably we had more examples of some types of project than other; however this cannot be taken as an indicator that such projects were more numerous in the total population of urban energy initiatives. We did not attempt to gather a comprehensive catalogue of all such projects in operation at a point in time or a representative sample; rather this was a database of types of urban energy initiatives defined by their

\footnotetext{
${ }^{2}$ The 14 different types of technology were the following: air source heat pump (ASHP), biomass, combined heat and power (CHP), geothermal, ground source heat pump (GSHP), hydro, insulation, solar PV, solar thermal, waste, wind, anaerobic digestion (AD), aquifer thermal energy storage (ATES), community heating/ district heating $(\mathrm{CH} / \mathrm{DH})$.
} 
combinatorial features and we focussed on finding examples of new and different types of initiative. Using this approach, we identified 182 projects in the UK ${ }^{3}$.

Following through on the co-evolution approach, we analysed in detail how different governance, economic, social and technical aspects of these projects were relationally combined with each other to produce distinct 'pathways' of change in urban energy systems. Each of the different pathways we identified had a distinctive combination of governance, economic, social and technological dimensions for an urban energy initiative. As we had four sub-categories under each of our four main dimensions, if all the cells in the matrix were populated there would be $256\left(=4^{4}\right)$ possible combinations. However by sorting, we could group the 182 recorded initiatives into similar combinations of the governance, economic, social and technological dimensions - that is, matching the sub-categories for each initiative; this resulted in 51 distinct urban energy pathways. Mind-mapping software was used to illustrate these; Figure 1 gives an example of such a mapping for pathways led by local authorities ${ }^{4}$. The following section analyses these 51 distinct pathways and this provides the basis for the final section, where we discuss the implications for urban governance and carbon reduction.

[INSERT FIGURE 1]

\section{Multiple pathways of change in urban energy systems}

An initial analysis of the 51 different types of UK urban energy projects looked at the governance, economic, social and technological dimensions separately. This is

\footnotetext{
${ }^{3}$ The full database is available on the project's website at...

${ }^{4}$ All four mapping diagrams are available at ... and on the journal's website.
} 
illustrated in Figures 2-5. Figure 2 shows that very few (2\%) of the identified pathways were private sector-led. The remainder were fairly evenly distributed: $36 \%$ were led by a third sector organisation; $31 \%$ by a partnership; and $31 \%$ by a local authority.

\section{[INSERT FIGURES 2-5]}

Considering the role that different packages of economic instruments played in creating distinct pathways, it is clear that subsidies dominated. In almost three quarters (74\%) of all pathways subsidies were the main economic instrument used; in another $17 \%$ they were combined with reliance on the feed-in tariff. Such subsidies came from a wide variety of sources: the European Commission, the utilities, local authority budgets, or central government schemes bid for by communities to name a few; examples are given in case studies below. There were, though, $7 \%$ of pathways where there was no discernible economic policy instrument involved.

Turning to the social dimension, public involvement was a significant but not dominant feature of urban energy initiatives. Just above a quarter (28\%) of pathways involved both public awareness-raising and more intensive public engagement and another $15 \%$ involved one or the other. However, more than half $(57 \%)$ of the pathways did not involve any discernible level of public involvement.

Finally, looking at the involvement of technology in defining projects, energy generation technology on its own was the focus in half $(51 \%)$ of the pathways and in another $22 \%$ it was involved in combination with demand management technology. Demand management technology on its own was involved in $15 \%$ of pathways and there were only $12 \%$ that did not involve technology at all. 
This emphasises the diversity complexity of current urban energy pathways, confirming the argument put forward by Geels and colleagues (2008). However, the co-evolution frame encourages us to look at the inter-relationships between the governance, economic, social and technological dimensions of urban energy projects and consider how different pathways combine these dimensions in distinctive ways. The rest of this section looks at these different urban energy pathways in more detail. We could have used any of our four dimensions to organise this analysis; it would not affect the identification of the individual pathways. However we have chosen to use the governance dimensions as the starting point and organise the analysis under the categories of our governance dimension. This partly reflects our own research interests but also highlights the importance of the actors initiating these projects in a way that the other dimensions do not. However, as will be seen, there is much more complexity than is implied by this four-way presentation of different governance categories.

\section{Local authority-led pathways}

Looking at initiatives typified by the local authority-led pathways, two main patterns can be identified among the 12 distinctive combinations. First, there are a number of schemes where the local authority does not rely on any economic tools or any form of public involvement but simply invests directly in a range of technological options in pursuit of energy and financial savings. For example, Barnsley Council has installed a $500 \mathrm{~kW}$ biomass boiler at its Westgate Plaza headquarters as part of its 'Econergy Initiative’ with reported savings of over $£ 500 \mathrm{k}$ p.a. for an initial additional capital cost of $£ 132 k$ (NewEnergyFocus 2008; IctActive 2010). Similarly the London Borough of Brixton has invested in a full energy-efficiency retrofit at its council estate in Angell Town, with the effect of halving energy consumption (Sustainable Homes 2004). 
Second, we found local authority-led schemes that rely on subsidies, sometimes combined with price the feed-in tariff use this to support a range of different kinds of public involvement and a range of different kinds of technological applications. Subsidies seem to go with innovation and flexibility in local authority action on urban energy and local authorities have used this to extend their involvement with local communities in a variety of ways. The initiatives under the Greater London Authority's Low Carbon Zones fall into this category. For example, the Wandle Valley Project has installed PVs on local schools and free energy saving devices in 500 homes but also undertaken a range of low carbon education activities, including the recruitment of two Green Doctors, energy advice surgeries and a Climate Change Volunteers scheme (Groundwork 2010; Merton Council 2010).

\section{Private sector-led pathways}

Private sector-led projects cover private companies and businesses investing in decentralised energy in urban areas. Here we sought to focus on initiatives that extended beyond the individual private building. It is notable that we identified only two distinct pathways, perhaps suggesting established path dependencies in how the private sector operates. Sometimes economic instruments were relied on and sometimes they were not but, in no case was there any public involvement activity. These projects focussed on the installation of energy generation technology, although demand management technologies may be 'hidden' through routine installations in new developments under the requirements of planning and building control. An example is provide by the scheme in Lyme Regis, Dorset, where a private trust installed a micro hydro-electric system at Town Mill, partially funded by a Clearskies Renewable Energy Grant and the EDF Energy Green Fund (The Town Mill 2010). Green Park Wind Farm in Reading is another example where a private 
developer, the Prudential, and the energy supplier, Ecotricity, invested in the installation of a $2 \mathrm{MW}$ wind turbine, selling energy to a business park and 1000 adjacent homes.

\section{Third sector-led pathways}

Third sector-led initiatives include initiatives headed by community groups, nongovernmental organisations (NGOs) and housing associations (non profit associations which provide 'social housing'). There were 18 pathways which fell broadly into three groups.

The first group were notable for their lack of public involvement and involved action to install new generation technology or manage demand, sometimes with a subsidy, sometimes not. These are comparable to many private sector pathways and the first local authority pathway we identified. All these different actors saw a rationale in direct investment in new energy technology.

The second group focussed on the use of the feed-in tariff either on its own or with subsidies, to support energy generation technology and sometimes additional demand management measures. Unlike the first groups of pathways, these were associated with various forms of public involvement. For example, the Transition Streets Project in Totnes, Devon has tapped into feed-in tariff agreements by installing PVs on the local town hall. This builds on Transition Towns Totnes, a community-led initiative now funded under the Government's Low Carbon Community Challenge Programme and involves extensive public engagement through 'Transition Together', a behaviour change programme which is a prerequisite for subsidised retrofits and low interest loans for PVs (Transition Town Totnes 2009). 
The remaining third sector pathways were very diverse in kind. Sometimes they involved subsidies, sometimes not; they could involve generation technology or demand management technology or neither. They are distinguished though by the presence of different forms of public engagement. For example, the Bristol Green Doors Project is led by a voluntary organisation and seeks to facilitate energy awareness and promote home retrofitting; it offers advice and publicises demonstration homes. Funding is received from some local businesses but not from the government (Bristol Green Doctors 2010).

Overall, these third sector pathways generally demonstrated some form of public involvement, with 14 of the 18 pathways (78\%) including public awareness and/or engagement activities. This might be expected due to the nature of the third-sector groups involved in project governance and their inherent values but it may also be that these are more complex projects, often combining energy generation and demand management and thus necessitating greater public involvement.

\section{Partnership-led pathways}

Partnerships are multi-agency bodies providing leadership to a group of organizations. They can include local government, housing associations, local service providers, residents and community-based organizations but sometimes local businesses as well. The partnership project types fell into 19 different pathways which followed three main patterns.

The first pattern involved subsidies, sometimes supplemented by the feed-in-tariff. As with the local authority-led projects, the presence of subsidies was associated with a variety of forms of public involvement and of technological possibilities. For example, the Cirencester Energy Neighbourhood Project received European funding 
through the Intelligent Energy Europe Grant Fund to encourage energy saving through changes in behaviour. Households formed Energy Neighbourhood Teams and, under the guidance of an Energy Master, used a toolkit to monitor and reduce their consumption. The partnership here involved Cirencester Council, Severn Wye Energy Agency and two housing associations.

The second parallel pattern involved a reliance on the feed-in tariff, sometimes supplemented by subsidies. Energy generation technology was always involved (of necessity given the nature of the feed-in-tariff) and sometimes demand management technology was also included. Public involvement took different forms or was absent. For example, the Sustainable Moseley Project in Birmingham, where partnership between community organisations, housing associations, schools and churches was leading a programme of PV installation and resident-led campaigning for behavioural change. Funding here came from the British Gas Green Streets Programme.

The third pattern included pathways which did not rely on any economic tools or involve any public involvement; they focussed simply on energy generation technologies, again echoing a pattern found in other governance categories.

As with third-sector led initiatives, the 19 partnership pathways included 12 pathways with some form of public involvement (63\%), perhaps for similar reasons.

\section{Conclusions: the implications of multiple pathways for change}

It is clear from this analysis that there is considerable complexity within the current changes affecting urban energy systems. Following Geels et al. (2008), current attempts at un-locking from the centralization of the UK energy system is resulting in 
a proliferation of pathways, particularly outside the private sector (Leach, Scoones et al. 2010). This is most apparent if attention is drawn not just to the technology being used but also to the economic, social and governance dimensions of change in urban energy systems.

Some patterns can be discerned among the multiple pathways. Across all sectors that might initiate or lead on a pathway, there was scope for direct investment in new technology without reliance on economic policy instruments or the involvement of the public. However, it was also clear that financial instruments were important in promoting new pathways. At the time of the research, the feed-in tariff was acting as a key stimulus but subsidies also played a significant role. Such subsidies were notable for their variety and flexibility in supporting a variety of different kinds of pathways. Over half of all pathways proceeded without public involvement, suggesting that the much vaunted shift of households to energy 'prosumers' or 'energy citizens' will largely have to rely on individual rationality rather than a collectively-driven shift in societal values and community action. It was in the pathways promoted by the third sector and partnership bodies that public involvement, particularly intensive public engagement was most apparent; and these pathways were also the most diverse and heterogeneous. Private sector pathways, by contrast, were less varied and were characterized by the absence of public involvement.

Overall the emergence of new pathways in locations across the UK points to considerable innovation and experimentation. But as Geels and colleagues (2008) also emphasize not all the pathways tried out in early stages of a transition will succeed and be sustained into the future. As yet, in the midst of the period of experimentation, we cannot tell which pathways will die away and which will become 
more dominant. This has considerable implications for urban governance of change in energy systems at this scale.

First, this complexity and flux creates a considerable challenge for urban policy makers. We have seen that local authorities are often involved in leading decentralisation initiatives or are involved in partnerships that are taking such a leadership role. But overall planning on an urban scale goes beyond individual initiatives of these kinds. How can the local authority plan for and coordinate change at the urban scale when there is such multiplicity of diverse initiatives occurring?

Under the New Labour government, much more emphasis had been placed on infrastructure delivery within spatial planning. This was identified as a key element of local governance in the Local Government Act 2000 and the Local Government Act 2007 reinforced this together with the 2008 revision of Planning Policy Statement 12 (HMG 2000; HMG 2007; CLG 2008). Spatial planning at the local scale was intended to plan proactively for infrastructure investment alongside new urban development and in response to changing local demographic and economic needs. Such infrastructure was understood broadly to encompass transport, education and health services, water supply and drainage, but also energy supply. Local planning documents (within the Local Development Framework) were supposed to consider the need for and cost of new infrastructure investment, link this to the phasing of new urban development and identify both funding sources and responsible delivery agents. If necessary, any gap was to be filled by the Community Infrastructure Levy on new development (CLG 2010; CLG 2011).

This framework has not been completely dismantled with the advent of Localism and associated reforms to the planning system as set out in the Localism Act (HMG 
2011) and a range of associated policy changes (HMG 2010). Under this agenda, local communities and also businesses are able to draw up neighbourhood plans and engage more generally in local service provision. This could be seen to encourage the proliferation of different kinds of energy initiative that this paper has identified. However, central government guidance set out in the National Planning Policy Framework (CLG 2012) still expects local authorities to proactively plan for energy and heat infrastructure and to set strategic priorities for investment in such infrastructure. The quality and capacity of existing infrastructure is to be assessed and opportunities for when developments can draw on decentralised, renewable or low carbon energy sources identified. Local authorities are charged with investigating the potential co-location of the suppliers and consumers of heat and generally with supporting the delivery of infrastructure for a low carbon future. At the same time, they are to support community-led initiatives. To the extent that the private sector, the third sector and ad hoc partnerships do play a major role in initiating and investing in new urban energy pathways, this may create problems for local government seeking to coordinate and manage the overall pattern of infrastructure investment in urban energy systems. Second, it remains uncertain what the impact of current changes will be on carbon emissions. We have highlighted how each new pathway involves a specific combination of economic instrument, governance structure and public involvement strategy for any given technology. The effectiveness of the change in energy and carbon terms will rest as much on the appropriateness of this combination as the technical viability of a scheme. Furthermore we have shown that many of the new pathways involve demand management alongside energy generation and distribution options, working along the length of the energy chain from production to consumption. The extent to which 
demand management is successful in reducing energy consumption will, in many cases, affect the technical efficiency of the adopted technology in energy and carbon terms, since technologies such as heat networks and renewable energy generation schemes have an optimal scale of operation; economic viability may also be affected by such scale issues. Efficiency and viability is also affected by the balance between the demand for heat services (which can be reduced through insulation measures) and for electricity (where appliance use is important) and the impact of demand management measures on this balance. The rebound effect - whereby energy efficiencies and therefore financial savings result in greater expenditure elsewhere, including on other energy consuming activities - may also be significant and again alter the balance between heat and electricity (EST 2006; Brannlund, Ghalwash et al. 2007; Sorrell, Dimitropoulos et al. 2008).

Yet the impact of demand management initiatives is very difficult to predict since it depends on the effectiveness of public engagement activities in driving behavioural change (Lorenzoni, Nicholson-Cole et al. 2007; Owens and Driffill 2008). We have shown that over half of the pathways identified did not include any public involvement. Furthermore, our analysis has shown that where public involvement was included, there were a range of possible pathways, involving both public awareness and deeper engagement activities, often driven by community groups either leading initiatives or being part of partnerships. These different pathways are likely to have different effectiveness in terms of reducing demand. Therefore, it will be important to understand more about when and where specific pathways are emerging, whether and how they involve the public and how they are shaping energy demand before conclusions can be made about the impact of change in urban energy systems on carbon emissions. 
Thirdly, the complexity revealed by this focus on emerging pathways in a period of transition involves a different perspective on urban policy processes (Sanderson 2006; Rydin, Bleahu et al. 2012). As the above discussion has emphasised, such complexity makes strategic planning difficult and highlights the extent of unintended and unpredictable outcomes, particularly in relation to energy demand management. Instead recognising such complexity suggests prioritising experimentation through ad hoc projects and grass-roots initiatives. It also puts the emphasis on social learning by the actors involved. It is through such social learning that some pathways fade away and others come to dominate as actors become able to judge which options are most effective, efficient, viable and acceptable. The more that social learning can be facilitated, the more quickly a transition can be effected. The key problem is how learning in one specific urban context can be transferred to another. This involves both enabling communication between the initiators of projects in different locations and fostering the ability to make the lessons from one location relevant to the specific conditions in another.

The complexity of future possible pathways revealed by this analysis of current initiatives in urban energy systems thus suggests a transition to a 'second era' of decentralisation may be in process but that, to be successful, urban governance will need to adjust. It will need to consider how to mesh the support of community-based and market-led initiatives with a strategic approach to the planning of urban energy infrastructure and accept the difficulties of predicting demand for energy services in relation to supply options. Instead, an emphasis on project-based experimentation should be accepted and social learning facilitated across project-based groups of stakeholders, particularly in relation to the implications of creating packages of measures to support specific pathways. Understanding the effectiveness of demand 
management measures within these packages will be a significant challenge. Such social learning will be essential in determining which pathways survive to constitute any new era in energy systems.

\section{Acknowledgements}

This paper is based on research undertaken under Sustainable Urban Environments programme Phase 3 funded by the Engineering and Physical Sciences Research Council (EPSRC), grant number EP/1002170/1. We wish to acknowledge the contribution of our fellow team members to the development of the thinking underpinning this paper. 


\section{References}

Ackerman, T., G. Andersson, et al. (2001). "Distributed generation: a definition." Electric Power Systems Research 57: 195-204.

Alanne, K. and A. Saari (2006). "Distributed energy generation and sustainable development." Renewable and Sustainable Energy Reviews 10: 539-558.

Allen, P., M. Fitzsimmons, et al. (2003). "Shifting plates in the agrifood landscape: the tectonics of alternative food initiatives in California." Journal of Rural Studies 19(1): 61-75.

Arthur, W. B. (1989). "Competing technologies, increasing returns, and lock-in in hidstorical events." The Economic Journal 99: 116-131.

Bergman, N. and N. Eyre (2011). "What role for microgeneration in a shift to a low carbon domestic energy sector in the UK?" Energy Efficiency.

BERR (2008). Microgeneration Stretegy Progress Report. London, BERR.

Betsill, M. and H. Bulkeley (2007). "Looking Back and Thinking Ahead: A Decade of Cities and Climate Change Research." Local Environmeant 12(5): 447-456.

Brand, R. (2005). Syncronizing Science and Technology with Human Behaviour. London, Earthscan.

Brannlund, R., T. Ghalwash, et al. (2007). "Increased energy efficiency and the rebound effect:

Effects on consumption and emissions." Energy Economics, 29(1): 1-17.

Bristol Green Doctors (2010) The Bristol Green Doctors Project.

CLG (2008). Planning Policy Statement 12: Local Spatial Planning. department for Communities and Local Government (CLG). London, HMSO.

CLG (2010). The Community Infrastructure Levy: Summary. London, Department for Communities and Local Government (CLG).

CLG (2011). Community Infrastructure Levy: An Overview. London, Department for Communities and Local Government (CLG).

CLG (2012). National Planning Policy Framework (CLG).

Coaffee, J. (2008). "Risk, resilience and environmentally sustainable cities." Energy Policy 36(12): $4633-4638$.

DECC (2009). Low Carbon Transition Plan. London, Department for Energy and Climate Change.

DECC (2011) Huhne takes action on Solar farm threat.

DECC (2011). Renewable Heat Incentive. Department for Energy and Climate Change (DECC). London, HMSO. 
DTI (2006). Distributed energy: A call for evidence for the review of barriers and incentives to distributed electricity generation, including combined heat and power. A Joint DTI-Ofgem Consultation. London, Department of Trade and Industry (DTI).

DTI (2006). The Microgeneration Strategy: Our energy challenge - power from the people. London, Department for Transport and Industry.

EST (2006). Rise of the Machines: A Review of Energy using Products in the Home from the 1970s to Today. London, Energy Saving Trust.

Evans, R., S. Guy, et al. (2001). "Views of the City: Multiple Pathways to Sustainable Transport Futures." Local Environment 6(2): 121-133.

Geels, F. W. (2005). "Co-evolution of technology and society: The transition in water supply and personal hygiene in the Netherlands (1850-1930) - a case study in multi-level perspective." Technology in Society 27(363-397).

Geels, F. W. (2005). Technological Transitions and System Innovations. A Co-evolutionary and SocioTechnical Analysis. Cheltenham, UK and Northampton, USA, Edward Elgar.

Geels, F. W., H. M. P, et al. (2008). "The micro-dynamics of sustainable innovation journeys." Technology Analysis and Strategic Management 20(5): 521-536.

GOS (2008). Powering our Lives: Sustainable Energy Management and the Built Environment. Final Project Report. London, Government Office for Science (GOS).

Groundwork (2010) Green Doctors in Wandle Valley Low Carbon Zone.

Guy, S. (2006). "Designing urban knowledge: competing perspectives on energy and buildings." Environment and Planning C 24: 645-659.

Guy, S. and G. Farmer (2001). "Reinterpreting Sustainable Architecture: The Place of Technology." Journal of Architectural Education 54(3): 140-148.

Guy, S., S. Graham, et al. (1997). "Splintering Networks: Cities and Technical Networks in 1990's Britain." Urban Studies 34(2): 191-216.

Guy, S. and S. Marvin (2001). "Constructing sustainable urban futures: from models to competing pathways, Impact Assessment and Project Appraisal." Journal of the International Association for Impact Assessment 19(2): 131-139.

Guy, S. and S. A. Moore (2007). "Sustainable Architecture and the Pluralist Imagination." Journal of Architectural Education 60(4): 15-23.

Guy, S. and E. Shove (2000). A Sociology of Energy, Buildings and the Environment: Constructing Knowledge, Designing Practice. London, Routhledge.

Hess, D. J. (2007). Alternative Pathways in Science and Industry: Activism, Innovation, and the Environment in an Era of Globalization. Cambridge, MA, MIT Press.

HMG (2000). Local Government Act 2000. Her Majesty Government (HMG). London, HMSO. 
HMG (2007). Local Government and Public Involvement in Health Act 2007. Her Majesty Government (HMG). London, HMSO.

HMG (2010). Decentralisation and the Localism Bill: an essental guide. London, CLG.

HMG (2011). Ther Localism Act. London, HMSO.

HMSO (2004). The Energy Act. Her Majesty's Stationery Office. London.

HMSO (2006). Climate Change and Sustainable Energy Act. Her Majesty's Stationery Office. London.

IctActive (2010) Westgate Plaza One, Barnsley, South Yorkshire.

Jamison, A. (2001). The Making of Green Knowledge: Environmental Politics and Cultural

Transformation. New York, Cambridge University Press.

Leach, M., I. Scoones, et al. (2010). Dymanic Sustainabilities. London, Earthscan.

Leach, M., I. Scoones, et al. (2010). Dynamic Sustainabilities - Technology, Environment and Social Justice. London, Earthscan.

Lorenzoni, I., S. Nicholson-Cole, et al. (2007). "Barriers perceived to engaging with climate change among the UK public and their policy implications." Global Environmental Change 17(3-4): 445-459

Marvin, S., H. Chappells, et al. (1999). "Pathways of smart metering development: shaping environmental innovation." Computers Environment and Urban Systems 23: 109-126.

Merton Council (2010). Wandle Valley Low Carbon Zone NEWS. London, Merton Council.

Moore, S. A. (2007). Alternative Routes to the Sustainable City: Austin, Curitiba, and Frankfurt. Lanham, MD, Lexington Books.

NewEnergyFocus (2008) Red tape hinders Barnsley's biomass fuel conversion efforts.

Owens, S. and L. Driffill (2008). "How to change attitudes and behaviours in the context of energy." Energy Policy, 36(12): 4412-4418.

Pepermans, G., H. Driesen, et al. (2005). "Distributed generation: definition, benefits and issues." Energy Policy 33(6): 789-798.

Reid, A. and K. Allen (1970). Nationalised Industries. London, Penguin.

Roberts, S. (2008). "Energy, equity and the future of the fuel poor." Energy Policy 26: 4471-4474.

Rydin, Y. (2010). Governing for Sustainable Urban Development. London, Earthscan.

Rydin, Y., A. Bleahu, et al. (2012). "Shaping cities for health: the complexity of planning urban environments in the 21st century." The Lancet. 
Sanderson, I. (2006). "Complexity, 'practical rationality' and evidence-based policy making." Policy and Politics 34: 115-132.

Shove, E. (2003). Comfort, Cleanliness and Convenience. The Social Organisation of Normality. Oxford and New York, Berg.

Sleeman, J. (1953). British Public Utilities. London, Issac Pitman.

Sorrell, S., j. Dimitropoulos, et al. (2008). "Empirical estimates of the direct rebound effect: A review." Energy Policy 37(4): 1356-1371.

Sperling, K., F. Hvelplund, et al. (2010). "Centralisation and decentralisation in strategic municipal energy planning in Denmark." Energy Policy 39: 1338-1351.

Sustainable Homes (2004). Good Practice Guide - Refurbishments. Kingston-upon-Thames, Sustainable Homes.

Taylor, D. (2000). "The rise of the environmental justice paradigm: injustice framing and the social construction of environmental discourses." American Behavioural Scientist 43(4): 508-580.

The Town Mill (2010). News from the Grindstone. Lyme Regis, The Town Mill Trustee.

Transition Town Totnes (2009) Transition Streets : Transition Town Totnes Earns Substantial Government Support!

Unruh, G. (2000). "Understanding carbon lock-in." Energy Policy 28(12): 817-830.

Unruh, G. (2006). "Globalising carbon-lock-in." Energy Policy 34: 1185-1197.

Watson, J. and P. Devine-Wright (2011). Centralisation, decentralisation and the scales in between: What role might they play in the UK energy system? The Future of Electricity Demand. Customers, Citizens and Loads. T. Jamasb and M. Pollitt. Cambridge, Cambridge University Press.

Wolfe, P. (2008). "The implications of an increasingly decentralised energy system." Energy Policy 36: 4509-4513.

Woodman, B. and P. Baker (2008). "Regulatory Frameworks for Decentralised Energy." Energy Policy 36: 4527-4531. 
Figure 1 - An illustration of mapping urban energy pathways: local authority-led project pathways (12 distinct pathways)

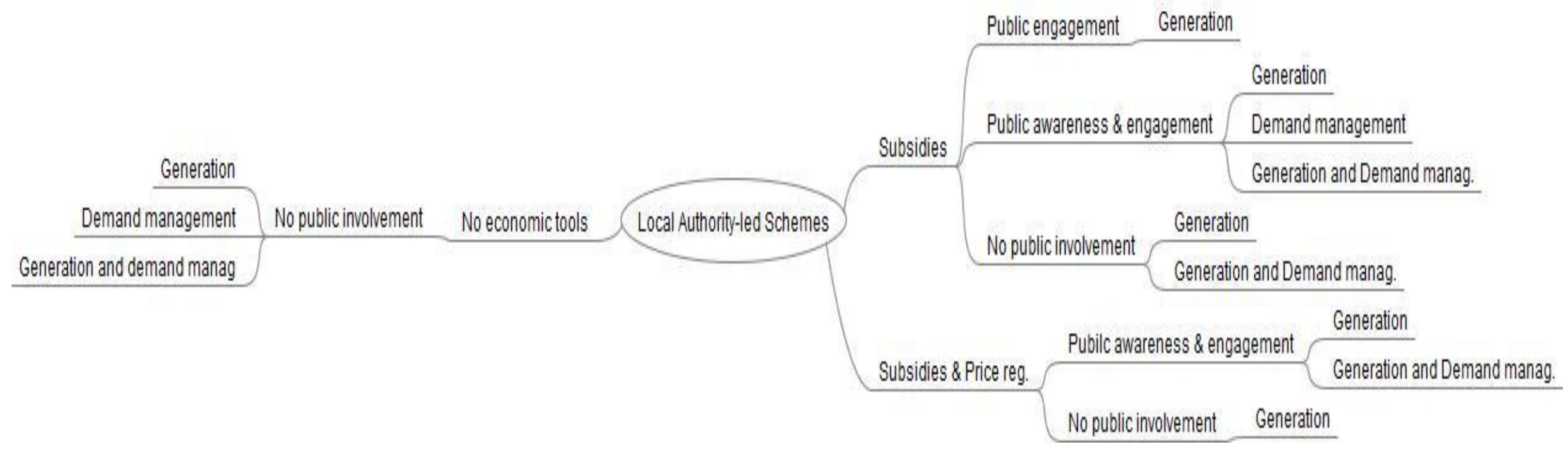


Figure 2 - Distribution of governance pathways in urban energy projects

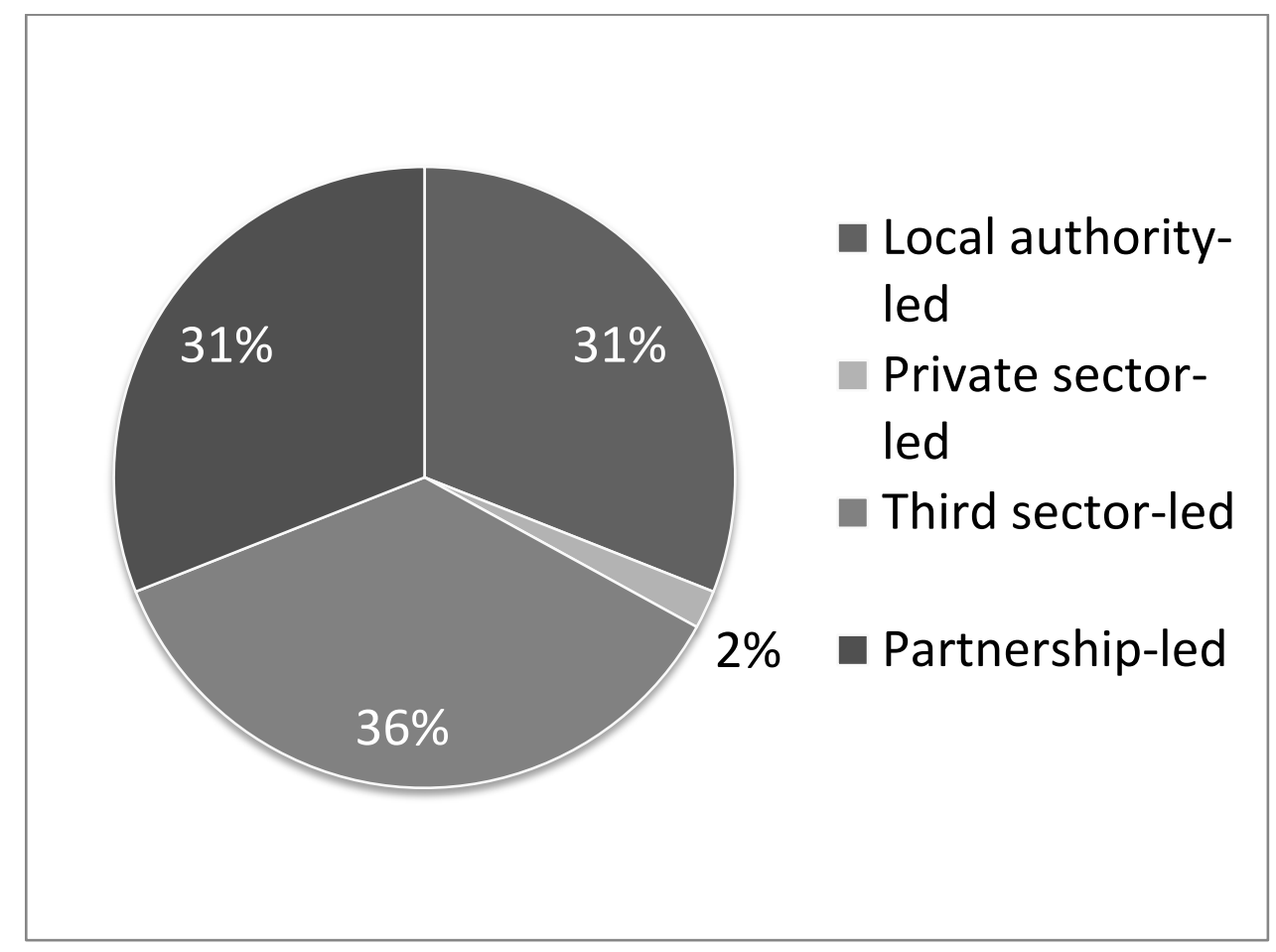

Figure 3 - Distribution of economic tools pathways in urban energy projects

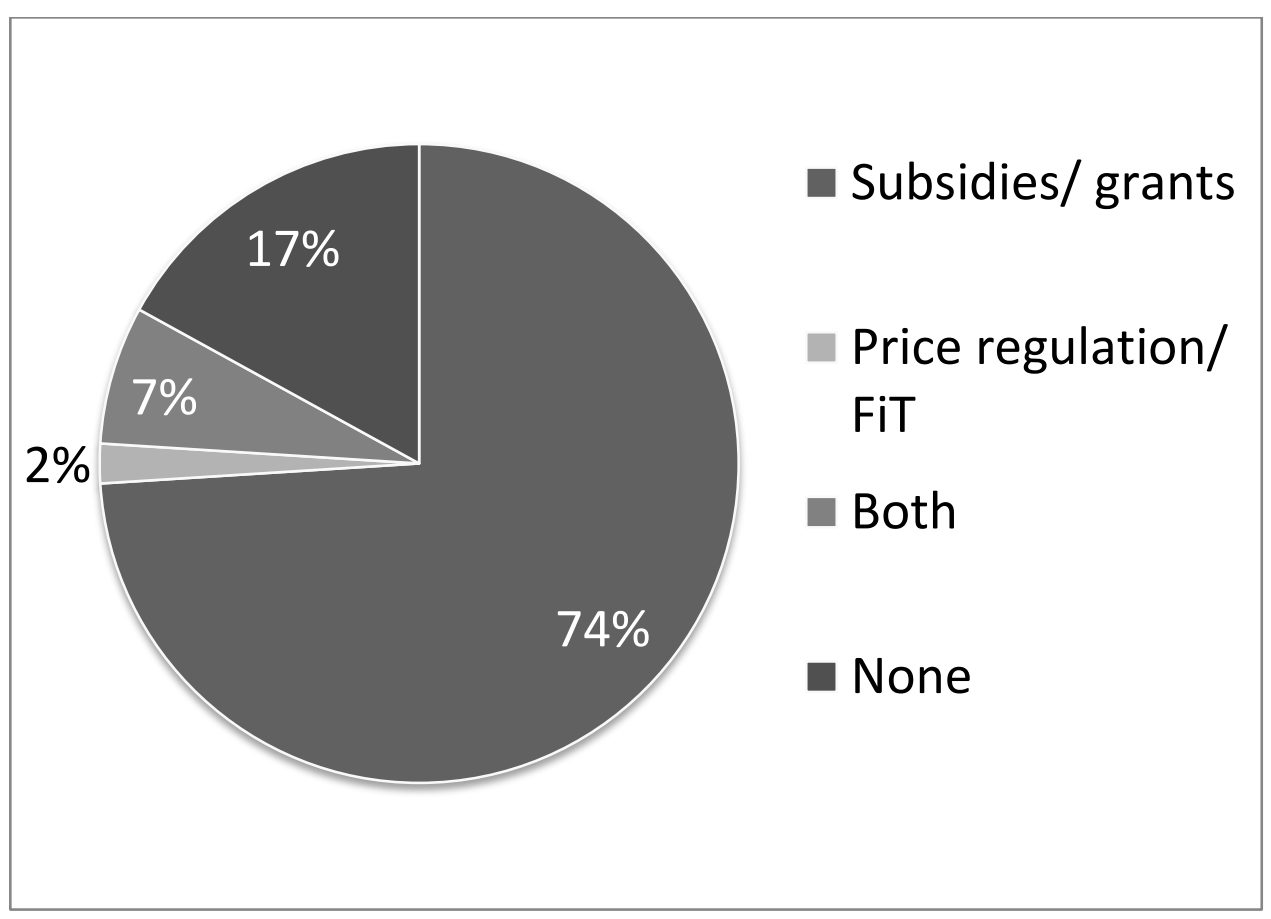


Figure 4 - Distribution of public involvement pathways in urban energy projects

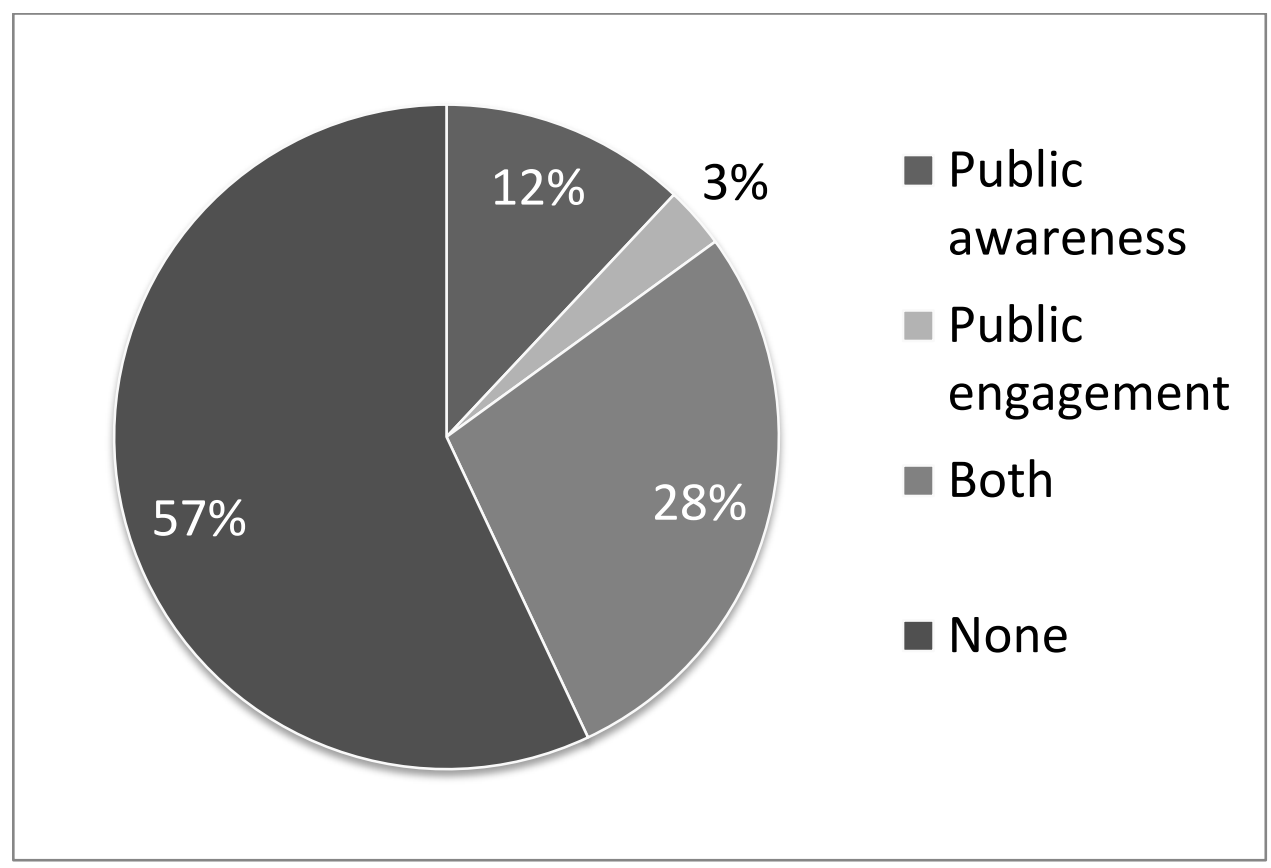

Figure 5 - Distribution of technological pathways in urban energy projects

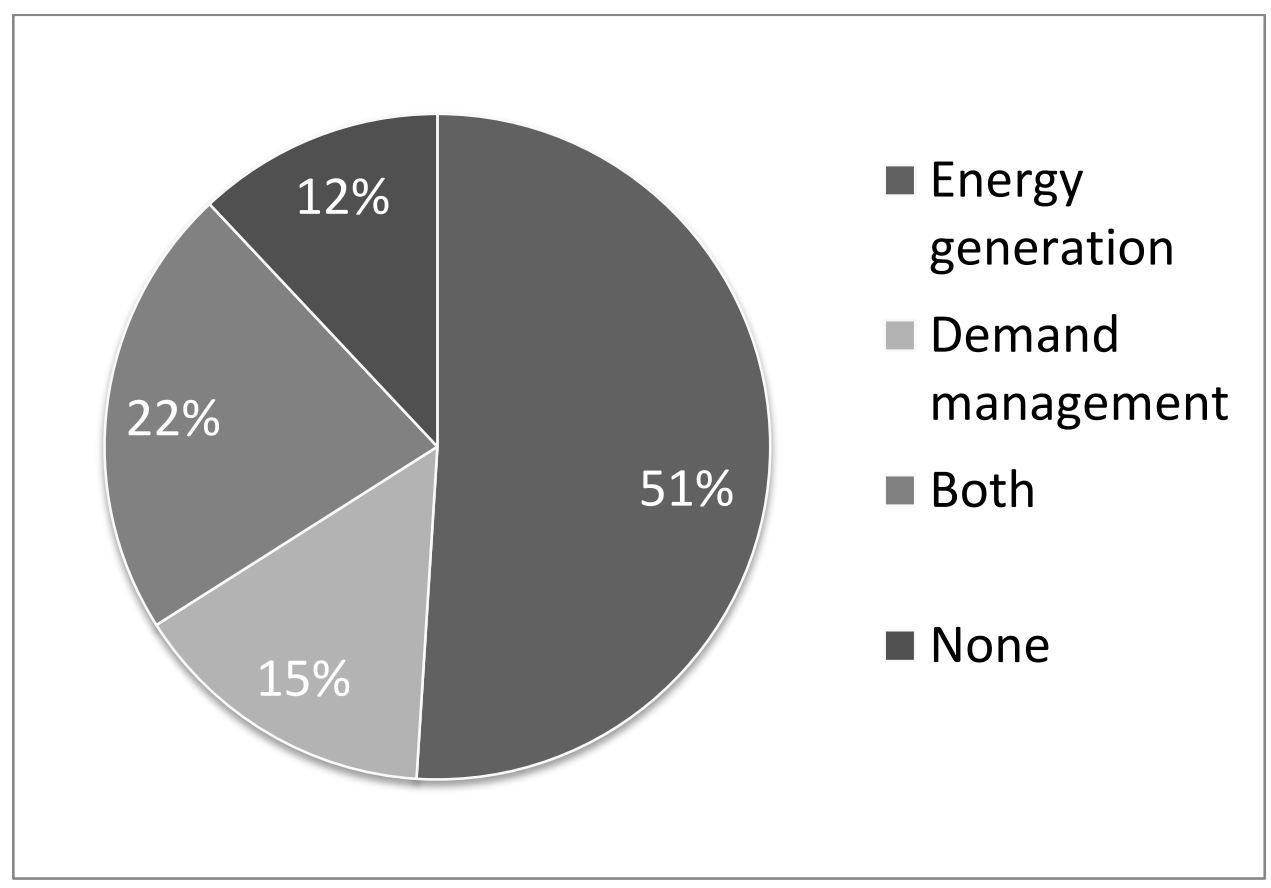

